\title{
Invitro Studies on Antidiabetic Effect of Aegle Marmelos Plant Aqueous Extract
}

\author{
Marypatience Muyuka. Msc
}

\begin{abstract}
Diabetes has become a major metabolic disorder disease that is increasingly becoming a killer disease worldwide. The aim of this study was to evaluate (bael tree) Aegle marmelos plant extract has the potential efficiency to manage diabetesmellitus type 2, that affects kidney and liver, in streptozotocin induced rats. Wister strain male rats were used grouped into three groups.The first group was used as control, the second group was induced diabetes by inducting streptozotocin $70 \mathrm{mg} / \mathrm{kg}$, the third group was induced diabetes and treated with A.marmelosaqueous plant leaves extract in the increasing dosage of $250 \mathrm{mg} / \mathrm{kg}, 350 \mathrm{mg} / \mathrm{kg}$ and $450 \mathrm{mg} / \mathrm{kg}$ body weight from the 3rd to 21stday. Induction ofstreptozotocin affected the liver, kidney and their histopathology. Biochemical tests andhistopathological studies were conducted. After administration of Aegle marmelos extract in increasing level, glucose level was significantly $p<$ 0.05 reduced. The Kidney and liver parameters creatinine, urea, cholesterol protein, alanine transaminase (ALT), as partatetransaminase (ALT), alaninephosphate (ALP), albumin were also significantly $p<0.05$ reduced from16th day of study. Histopathalogical results showed reduced inflammatory cellular lining inliver for the rats that were treated with the aqueous plant extract after inducing diabetes, whilethe histopathological test for pancreas showed reduced focal damage for the animals that were treated with the plant extract after inducing diabetes. From this results we found that Aegles Marmelos plant has therapeutic effect as renoprotective, hepatoprotective, and hypoglycaemic.
\end{abstract}

Keywords:

\section{Introduction}

About 347 million people have diabetes in adult population 20-79 years old. USA and Caribbean region have a higher prevalence of $11 \%$ while Middle East and North Africa are next with $9.2 \%$ reported by World Health Organization(25). India is the top country with the highest number of diabetic patients in the world followed by China. This number is expected to rise. Although Africa still faces other challenges and not many people have done diabetes test, diabetes could also become a major challenge(11). South Africa, Nigeria, Kenya and Mozambique that have better economies could face this problem as a major challenge in future.

\section{Management}

Metformin is a commonly used as an oral anti-diabetic drug currently.Overweight patients mainly prefer it since it is considered weight neutral. It is under biguanide class and works by reducing hepatitis glucose. The most adverse effect isgastrointestinal irritation (9). Metformin is used in setting of mild-moderate renal insufficiency.

In traditional days and today also, some herbs have been used to control and manage diabetes such as:

Ginseng has shown to fight diabetes (a 2000 study at Toronto University) revealed that 3 gram dose of ginseng extract significantly reduce the blood sugar spike, which occurs after taking a high carbohydrate meal. Holy basil also known as tulsi has shown to reduce both blood sugar and lipid levels. About $20 \%$ of blood sugar is reduced $(2,13)$. Annona squamosal extract has also revealed to potentially reduce diabetes (6). The Neem plant has also got antidiabetic and antihyperlipidemic effect (3). Bitter melon 3-6 tablespoon daily juice helps cells to use glucose more effectively and block sugar absorption in the intestines (22)

Gymnema Sylvester a Hindi name translates as sugar destroyer and the plant is said to reduce the ability to detect sweetness. It is regarded the most powerful herbs it may work as boosting the activity of enzymes that help use glucose or stimulates production of enzymes. (22).Aegles Marmelos a plant of Indian origin, with phytopharmacological properties has shown to reduce metabolic disorder such as cholesterol level and blood sugar levels. $(7,14,18)$.

\section{About Aegle Marmelos}

Aegle Marmelos is a plant that belongs to a family of rutaceae. It is 6-8 metres of height with aromatic leaves; flowers are nearly $2 \mathrm{~cm}$ wide boom in clusters, sweet scented and greenish white, the fruits are oblong pyriform in shape.(8)

This is a plant of Indian origin that a plays an important part in the Hindu religion (20). It is also present in South East Asia regarded as sacred tree. It grows in dry forests and hills. The plant has been used for so many pharmacological activities such us; antidyspepsia, antidiarrheal, antioxidants, as a laxative, antiulcer and cardio protective (10). It has also been used to inhibit antifungal activity and antibacterial activity (15).It is also used as pesticide and has shown to have nutritional properties. The parts of the plant were taken and all the structures were characterized by extensive 1D and 2D Nuclear Magnetic Resonance (NMR). From the roots, twigs and leaves consist of alkaloids and coumarins which include; oxazaline - 2-phenyl-5-(4-methoxyphynl)$\delta^{2}$-oxazoline(12). Skimmianine (Aurapten. Xanthotoxin) Marmin (20).

\section{Materials and Methods}

\section{Plant extract preparation}

Fresh leaves and twigs of the plant were collected from the green house under the guidance of a botanist. Using distilled water then cleaned them, shade dried and kept at room temperature in the department of botany. After drying, 


\section{International Journal of Science and Research (IJSR) \\ ISSN (Online): 2319-7064 \\ Index Copernicus Value (2013): 6.14 | Impact Factor (2015): 6.391}

$500 \mathrm{gms}$ of the plant leaves and twigs was taken powdered by crashing in a blender and mixed with $500 \mathrm{ml}$ of distilled water magnetically stirred overnight at room temperature. The extract was filtered and the aqueous extract was administered to animals

\section{Animals and drugs used}

Adult male albino rats Wister strain were taken, 100-120 days old.Institutional Ethics Committee approved the experiment and Care of Animals was carried out by guidelines of Committee for the Purpose of Control and Supervision of Experiment on Animals (CPCSEA), Ministry of Environment and Forest, Government of India. Each of these group was kept in propylene cage at ambient temperature of $24^{\circ} \mathrm{c}$ and $55 \%-65 \%$ relative humidity. A $12-$ hour light and dark schedule was maintained in the animal house until they are used to the laboratory condition they were then fed with commercial rat chaw and had free access to water. Streptozotocin was purchased from sigma chemicals and the other chemicals used were of analytical reagent grade.

\section{Experimental Design}

The animals were divided into 3 groups and the first group $\left(G^{1}\right)$ was used, as control thus there was neither induction of diabetes nor treatment with A. Marmelos aqueous extract. The second group $\left(G^{2}\right)$ was induced diabetes by treatment with streptozotocin through intraperitonial way and diabetes was confirmed by glucose test, after this confirmation only then the treatment of aqueous plant extract was commenced. The third group $\left(G^{3}\right)$ was treated with streptozotocin and A.Marmelos aqueous extract through intraperitonial way, the extract was given in increasing dosage of $250 \mathrm{mg} / \mathrm{kg}$, $350 \mathrm{mg} / \mathrm{kg}$ and $450 \mathrm{mg} / \mathrm{kg}$ body weight. This administration of A. Marmelos aquaes extract in group 3 was done twice daily in increasing dosage for 21 days to access the therapeutic potential of the plant extract.Pentathol sodium was used for sacrificing the groups of animals from the third day $, 7^{\text {th }}, 14^{\text {th }}$ day . Histopathological studies were also conducted in the liver and pancreas to check for toxicity. This was done by taking fresh fixatives samples and stored at $3^{\circ} \mathrm{C}$ and passed through alcohol solutions for dehydration.
They were washed in xylene and embedded in paraffin block cassettes. The tissues were sectioned in transverse, deparafinated and stained with haematoxylin and eosin. They were then examined under light microscope (x20) to view structural changes of the liver and pancreas.

\section{Biochemical tests}

Blood glucose was determined, kidney and liver parametersthat indicate effect of diabetes testwere analysed. For the blood glucose was determined by O-tulidine method. Cholesterol test was done by commercial kit method assay and Allain et al method. For the kidney test urea was tested by ChaneyMarbach method, creatinine test performed by Wit et al commercial kit assay method. Uric acid test was determined by Fossatai et al method and phosphorous was estimated by Endres et al method. For the liver,Aspartate transaminase (AST) was determined by Reitman et al method, Alkalinephosphate (ALP) was determined by King et al method, Alanine transaminase (ALT) was estimatedby estimated by assay kit (colorimetric and fluorometric) method.Albumin was analysed by BCG Assay kit.

\section{Statistical Methods}

All values of the biochemical estimations were expressed as mean \pm standard error mean (SEM) and were then analysed by ANOVA post hoc Dunnet t-test method using spss software $<0.05$ were considered to show statistically significant difference using spss version

\section{Results}

After induction of streptozotocin in increasing dosage of $250 \mathrm{mg} / \mathrm{kg}, 350 \mathrm{mg} / \mathrm{kg}, 450 \mathrm{mg} / \mathrm{kg}$ there was increased blood sugar levelTable. On administration of Aegles marmelos extract there wassignificant $\mathrm{p}<0.05$ controlwithin 14days.Hemoglobin levels were reduced in streptozotocin treated animals, treatment with A.m. extract significantly $\mathrm{p}<$ 0.05 increased. This could be because of improved sugar control by the plant extract.

Table 1: Efffect of A.m plant extract on serum glucose, hemoglobin,urea, cretinine,uric acid and phosphorous

Kidney parameters and serum glucose

\begin{tabular}{|c|c|c|c|c|c|c|}
\hline Group & glucose & Hbgm \% & Creatinine $\mathrm{mg} / \mathrm{dl}$ & Urea $\mathrm{mg} / \mathrm{dl}$ & Uric acid $\mathrm{mg} / \mathrm{dl}$ & Phosphorous $\mathrm{mg} / \mathrm{dl}$ \\
\hline control & $\mathbf{9 3 . 6} \pm \mathbf{6 . 7}$ & $\mathbf{1 5 . 6 5 2} \pm \mathbf{0 . 1 0 4}$ & $\mathbf{0 . 7 4 3} \pm \mathbf{0 . 1 0 8}$ & $\mathbf{5 2} \pm \mathbf{0 . 2 6}$ & $\mathbf{2 . 0 6} \pm \mathbf{0 . 2 5 2}$ & $\mathbf{7 . 1} \pm \mathbf{0 . 0 3}$ \\
\hline diabetic & & & & & & \\
& $\mathbf{2 1 1 . 4} \pm \mathbf{1 2 . 3}$ & $\mathbf{1 4 . 2 2 9} \pm \mathbf{0 . 3 7 1}$ & $\mathbf{1 . 2 3} \pm \mathbf{0 . 0 3 9}$ & $\mathbf{5 9} \pm \mathbf{0 . 7 5}$ & $\mathbf{3 . 6 5} \pm \mathbf{0 . 1 8 1}$ & $\mathbf{7 . 8} \pm \mathbf{0 . 0 2}$ \\
\hline treated & & & & & & $\mathbf{6 . 8} \pm \mathbf{0 . 4 5}$ \\
& $\mathbf{1 3 4 . 2} \pm \mathbf{6 . 4}$ & $\mathbf{1 5 . 6 7 9} \pm \mathbf{0 . 1 2 3}$ & $\mathbf{1 . 2 0} \pm \mathbf{0 . 1 2 5}$ & $\mathbf{5 8} \pm \mathbf{0 . 5 6}$ & $\mathbf{2 . 5 2} \pm \mathbf{0 . 2 5}$ & \\
\hline
\end{tabular}

The values are expressed in mean \pm S.D followed by pos hoc dunnet t-test.n=4 in each group.values that do not have a common superscript differ significantly $\mathrm{p}<0.05$.

Table 2: Effect of A.m plant extract on liver enzymes, cholestrol,albumin

\begin{tabular}{|c|c|c|c|c|c|}
\hline GROUP & AST $(\mathrm{U} \backslash \mathrm{L})$ & $\mathrm{ALT}(\mathrm{U} \backslash \mathrm{L})$ & $\mathrm{ALP}(\mathrm{U} / \mathrm{L})$ & Albumin $\mathrm{gm} \%$ & Cholestrol $\mathrm{mg} \%$ \\
\hline control & $\mathbf{3 4 . 8 3} \pm \mathbf{1 . 5 9 8}$ & $\mathbf{2 3 . 4 0} \pm \mathbf{0 . 7 9 4}$ & $\mathbf{2 1 0 . 1 4} \pm \mathbf{0 . 6 5 2}$ & $\mathbf{6 . 6 9} \pm \mathbf{0 . 0 0 6}$ & $\mathbf{3 4 . 8 0} \pm \mathbf{1 . 5 1 4}$ \\
\hline diabetic & $\mathbf{6 7 . 6 5} \pm \mathbf{2 . 5 4 6}$ & $\mathbf{1 5 . 9 5} \pm \mathbf{0 . 6 2 4}$ & $\mathbf{2 1 1 . 7 7} \pm \mathbf{1 . 4 8 2}$ & $\mathbf{5 . 6 3} \pm \mathbf{0 . 2 2 8}$ & $\mathbf{3 4 . 1 7} \pm \mathbf{0 . 8 0}$ \\
\hline treated & $\mathbf{6 2 . 4 6} \pm \mathbf{1 . 3 6 6}$ & $\mathbf{1 8 . 6 5} \pm \mathbf{0 . 6 2 4}$ & $\mathbf{2 1 0 . 9 8} \pm \mathbf{0 . 6 7 8}$ & $\mathbf{6 . 7 3} \pm \mathbf{0 . 3 2 1}$ & $\mathbf{3 4 . 2 3} \pm \mathbf{0 . 2 6 8}$ \\
\hline
\end{tabular}

The liver parameters 


\section{International Journal of Science and Research (IJSR) \\ ISSN (Online): 2319-7064}

Index Copernicus Value (2013): 6.14 | Impact Factor (2015): 6.391

The valuesare expressed in mean \pm S. $D$ followed by pos hoc dunnet t-test. $n=64$ in each group.values that do not have a common superscript differ significantly $\mathrm{p}<0.05$.

There was significant $\mathrm{p}<0.05$ increase in urea, uric acid and phosphorous in diabetic animals, whileA.m. extract treated animals had significant $\mathrm{p}<0.05$ decreasein Table 1.Hepatic enzymes in Table 2, significantly $p<0.05$ lowered after administration of A.m.extract. Cholestrol levels significantly $\mathrm{p}<0.05$ reduced after treatment with the plant extract. It is possible to predict that the A.m. plant extract may have degraded this cholesterol by inhibition of endogenous synthesis of the cholesterol. Albumin was significantly $\mathrm{p}<0.05$ increased in Table 2, after treatment A.m plant extract.

\section{Histopathology - Pancreas}

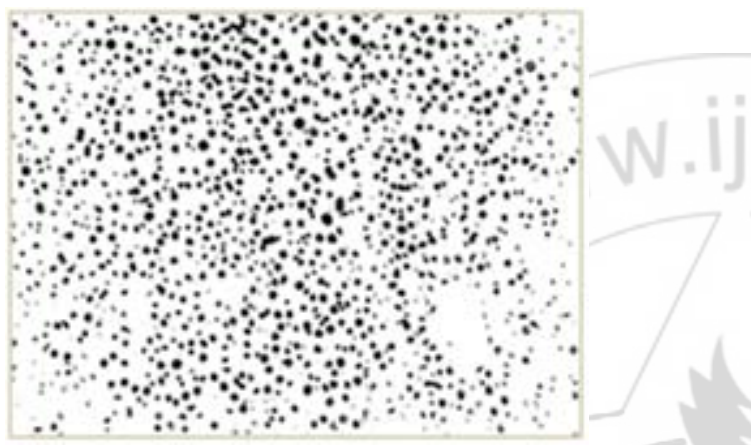

Section A. Normal architecture of Pancreas (control) (H\& E $\mathrm{x} 20)$

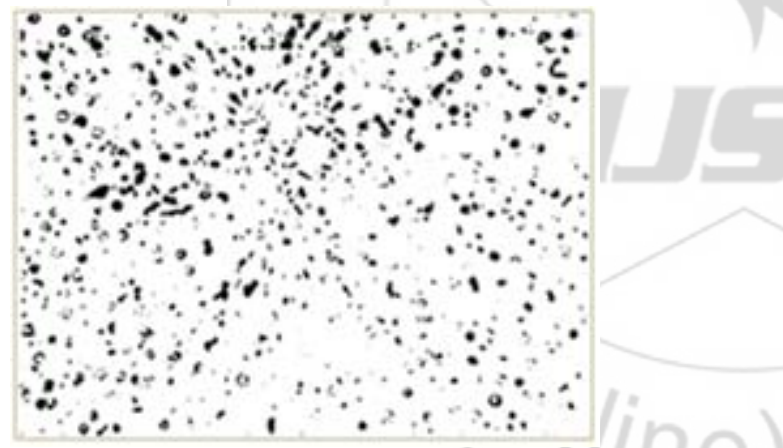

Section B. Pancreatic section showing two fold focal damage with inflammatory collections (STZ) (H \& E x20)

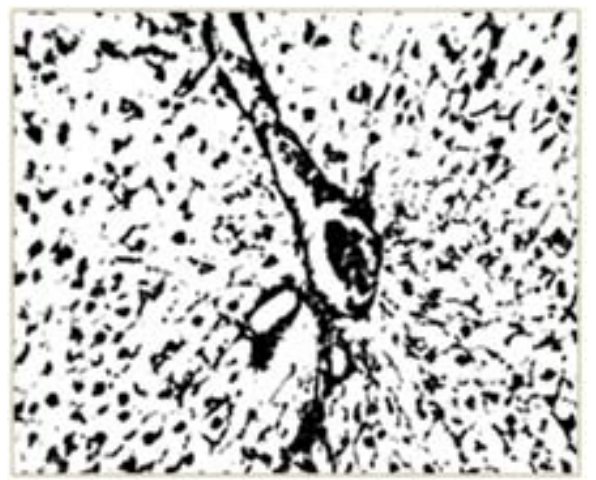

Section C. Pancreatic section showing reduced focal damage with inflammatory collections (STZ \& plant extract treated) (H \& E x20).

\section{Discussion}

The latest convention methods for treatment of diabetes have shortcomings such as side effect and others have failure in management. The plants have however shown to have no side effects but slow in efficacy.

In this study streptozotocin was used to induce diabetes since it is reported not to cause cell damage of the pancreas unlike nitric oxide. (16) Streptozotocin induction elevates the level of cholestrol (5) within the liver that are likely to increase the coronary disease. From our research, cholesterol test showed tremendous $\mathrm{p}<0.05$ reduction on treatment with the plant extract. This could be because of reduction in lipolysis. During diabetes the levels of cholesterol are increased, insulin depletes level of lipoprotein lipase leading to deranged lipids (26). Diabetes care 1991stated that reduction in lipids would be beneficial in long-term prognosis patients. This showed this plant extract could be useful in reducing hyperlipidaemia in diabetic patients (7). There wasincreased sugar levels in diabetic rats while those rats treated with plant extract showed lower glucose elevation thereby displaying improvement in glucose tolerance pattern (14), this means the plant utilized the blood glucose. This hypoglycaemic effect action was either by refurbishing the islet function increasing insulin output or by facilitation of metabolites generated due to insulin action. Diabetes has become the primary cause of renal disease (4). Induction of diabetes increased levels ofcreatinine, urea, uric acid and protein that indicates a kidney problem as stated by the American Diabetes Association. When the rats were treated with the extract there was much significance $p<0.05$ reduction of creatinine, urea uric acid and phosphorous. This displayed the plant extract as Reno protective (1). Glucose is usually absorbed from the intestinal tract to the portal vein then to the liver. Raised liver enzymes is characterised to insulin resistance (23). After treatment with Aegle marmelos plant extract in diabetic induced animals, there was significant $\mathrm{p}<$ 0.05 reduction in liver enzymes; alanine transaminase (ALT), aspartate transaminase (AST), and alanine phosphate (ALP). This could mean the plantextract reduced the excessive hepatic glycogen thus no deposit of glycogen and possibly decreased gluconeogenesis. Histopathological studies also proved the plant extract had no toxic effect to the organs but instead it displayed therapeutic effect to the kidney and pancreas (24).

\section{Contradiction}

When A.marmelosaqueous plant extract was induced into the animals the vital organs such as heart,liver,kidney and pancreas were takenand evaluated, there was no gross abnormalities from the histopathological result but instead displayed a therapeutically effect on the organs. (24)

\section{Conclusion}

The study results indicate the active compounds in the Aegle Marmelos aqueous extract may possessdiverse biological action andtherapeutic value based on its antidiabetic and antilipidemic. 


\section{International Journal of Science and Research (IJSR) \\ ISSN (Online): 2319-7064}

Index Copernicus Value (2013): 6.14 | Impact Factor (2015): 6.391

\section{References}

[1] Anusurallah Bhavna Bharucha, A.V.Ramachandran. Improved glycoregulation, insulin resistance Diabettologia Croatica 2012,41(1)

[2] Agrawal.P Rai V, SinghR.B.Randomized placebocontrolled single blind trial of holy basil leaves in patients with noninsulin -dependent diabetesmellitus. International journal of clinical Pharmacol 1996; 34:406-409.

[3] Bopana K.N, Kannnan J, Sushma Ganngil, Balaraman R, Rathod S.P.Antidiabetic and anti hyperlipidemic effect of neem, Lipidemic effect of neem seed kernel powder on alloxan diabetic rabbits. Indian journal of pharmacology 1997,29:162-167.

[4] Harper A.E.Glucose -6-phosphate, in: Bergmeyer H.U, edition. Methodsof enzymaticanalysis. New york: Academic Press, 1963:758.

[5] Karpen C.W, Pritchard K.A,Jr Merola A.J,Pangamala R.V.Alteration of the prostaglandin thromboxane ratio in streptozocin induced diabetic rats.Prostagland Leukotrien Med 1982;8:93-103.

[6] Kaleem M, Asif M, Ahmad Q.U, Bano B.antidiabetic and antioxidant activity of Annona squamosal extract in streptozotocin induced diabetic rat. Singapore medical journal.2006; 47:670-675.

[7] K. Devi, A Sivaraj, P.VinothKumar Syed Zame, Ahmed, KSathiyar. Hypolipidemic effect ofAegle Marmelos leaf extract. International Journal Pharmtech res.2010, 2(1) 265.

[8] Lambole V.B, Murti K, Kumar.V, Sandi P, Kumar P.B and Gajera V.Internatinal journal of Pharma Science. Review and Research, 2010:5:67-72.

[9] Lipska K.J, Bailey C.J, Inzucchi S.E .use of metformin in mild -to -moderate renalinsufficiency (Review) DiabetesCare. Journal of clinical pharmacy and therapeutics .2011,34:1431-143.

[10] Manjeshwar Shrinath Baliga Harshith P Bhat, Nandhini Joseph, Farhan Fazal Photochemistry and medicinal uses of the bael fruit. Food Research International. 2011,44(7); 1768-1775.

[11] Maria Azevedo, Sridevialla Diabetes in sub-saharan Africa: Kenya, Mali, Mozambique, Nigeria, South Africa and Zambia. International journal of diabetes in developing countries.2008; 289(4):101

[12] Mishara B.B, Singh, D.D, Kishore, N, Tiwani V.K, Tripathi .V. Antifungal constituents isolated from the seeds of Aegle Marmelos.2010, 71 (2-3): 230-4.

[13] Mondal S, Mirdha B.R,Mahapatra S.C .The science behind sacredness of Tulsi (Ocimum sactum linn).Indian J Physiol Pharmacol 2009;53(291-306)

[14], Mahapatra S.C.The science behind sacredness of Tulsi(Ocicum sactum linn). Indian journal of Pharmacol 2009; 53:291-306.

[15] N.Kamalakkanan, M, M, M, M. Rajadurai, P.Stanley, Effect of Aegle Marmelos fruits on normal and streptozotocin diabetic wistarrats. Journal of medicinal and food.2003; 3:93-98

[16] Pattrik s, Subramanyam V.R, Kole C. Antibacterial and antifungal activity of ten essential oils invitro microbes Scientific Publication Data.1996; 86[349]: 237-46.
[17] Rao V.S, Santos F.A, Silva R.M, Teixiera M.G.Effects of nitric oxide synthetize inhibitor and melatonin on the hyperglycaemic response to streptozotocin in rats. Vascular Pharmacol 2002; 38(3): 127-130.

[18]Richard Naha M.D and Mathew Moher, Complementary and alternative medicine for treatment of type II diabetes.2009

[19] Sabu Mc, Kuttan.R. Antidiabetic activity of Aegle Marmelos and its relationship with its antioxidant. Indian journal physiol Pharmacol,2004 48(1): 81-8.

[20] Sandoval DA, Davis SN.Leptin metabolic control and regulation. Journal of Diabetes 2003; 24:1-10.

[21] Surat Laphookhieo, Chalita Phungpanya, Cholpisut Tanntapukl, Somsak Techa, Suphara Tha-In.chemical constituents from Aegle Marmelos. Journal of the Brazilian chemical society 2011, vol 22(1).

[22] Sukhdev A, R. A selection of prime Ayurvedic plant drugs Ancient - modern concordance Anamaga Publication, Br Journal Surg; 62:542-552,1975.

[23] Syed Ibrahim Rizvi andNeetu Mishra Traditional Indian medicine usedformanagement of diabetes Mellitus. Journal of Diabetes Researchvol2013 Article ID 712092,11pages.

[24] Shreyas Saligram,Elibath J.William and Michael G Masding.Raised liver enzymes in newly diagnosed type 2 diabetes are associated with weigh and lipid not glycaemic control.Indian journal of Endroconology and Metabolism 2012,16(6): 1012-1014.

[25] Veerapan A, Miyazaki S, M Kadarkaraisamy, D Ranganathan.Acute and sub acute toxicity studies of Aegle Marmelos corr.an Indian medicinal plant. Phytomedicine 2007,vol 14:209-205.

[26] World Health Organization. Second report of the WHO expert Committee on Diabetes Mellitus. World Health Organization Tech repser 1980:646:1-80.

[27]Wang C.C, Goalstone M.L, DrazninBimolecular mechanism of insulin resistance that impact cardiovascular biology. Diabetes 2004; 53:2735-2740. 